
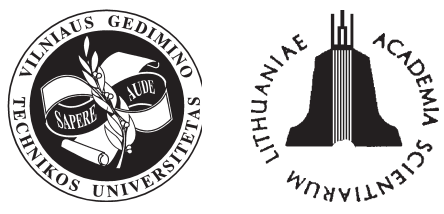

ISSN 1648-4142 TRANSPORT

www.transport.vtu.lt

\title{
EXPERIMENTAL RESEARCH INTO MOTOR VEHICLE OSCILLATIONS IN THE CASE OF CHANGEABLE DECELERATION
}

\author{
Robertas Pečeliūnas ${ }^{1}$, Olegas Prentkovskis ${ }^{2}$, Giedrius Garbinčius ${ }^{3}$, Saulius Nagurnas ${ }^{4}$, \\ Saugirdas Pukalskas ${ }^{5}$ \\ 1,3,4,5 Dept of Automobile Transport, Vilnius Gediminas Technical University, \\ J. Basanavičiaus g. 28, LT-03224 Vilnius, Lithuania.E-mail: tiauto@ti.vtu.lt \\ ${ }^{2}$ Dept of Transport Technological Equipment, Vilnius Gediminas Technical University, \\ Plytines g. 27, LT-10105 Vilnius, Lithuania.E-mail: olegas@ti.vtu.lt
}

Received 9 March 2005; accepted 25 June 2005

\begin{abstract}
In this paper processes of oscillation of flexible mounted and inflexible mounted masses are analysed. The tangential effect of the wheel contact with bearing surface is given, thus enabling more precise calculus of vehicle braking parameters. The methodology of research includes the development of mathematical algorithms and theoretical calculus of the analysed processes as well as the presentation of the influence of various factors on vehicle oscillations during braking. Analytical methods and those in figures have been applied for the research. Experimental investigations were carried out applying the electronic device VZM 100 measuring the acceleration of deceleration adapted for synchronous operation together with vibration processing system VAS21. The expert opportunities for modelling of vehicle movement are extended with the help of the created mathematical models used for the examination of road accidents related to vehicle braking.
\end{abstract}

Keywords: oscillation; deceleration; flexible mounted and inflexible mounted vehicle masses; braking.

\section{Introduction}

The suspension of a motor vehicle is one of the most important elements of the flexible mounted and inflexible mounted masses of the vehicle bodywork and most attention is paid to its exploration and improvement. The analysis of models of equivalent oscillation systems of motor vehicles testifies that the evaluation of motor vehicle oscillations and modelling of its motion modes is still very topical and requires further research. Suspension models of motor vehicles offered in publications regard only the influence of road irregularities and the modernisation of these models is directed towards the improvement of passengers' comfort [1-4]. However, not much research has been done into the influence of oscillations of flexible mounted and inflexible mounted masses of the bodywork of vehicles in the process of braking. There is also not much investigation of the post-accident identification of the vehicle movement mode corresponding to the deformations of the suspension and the longitudinal pitch of the bodywork [5]. The research of oscillations under the conditions of emergency braking is primarily important for the work in two practical directions:
- the improvement of calculation methods of motor vehicle response to external impact under the conditions of real operation;

- further improvement of research methods on the road and analysis of fait accompli road accidents related to oscillations in emergency braking.

The methodology defining the oscillations occurring in braking can be applied in the design and improvement of suspensions and other mechanisms as well as in the analysis of road accidents for the definition of motor vehicle motion mode according to the bodywork pitch angle. Therefore it is purposeful to analyse the oscillations of a motor vehicle in braking together with the evaluation of the impact of systems involved during the interaction of the vehicle and the road [6]. In summary, the following objectives and tasks can be formulated:

- To create an engineering method for the calculation of oscillations occurring during the vehicle braking. By selecting simplifications for engineering calculations, to maintain the equivalent vehicle oscillating system details at the same level as found in the theory and practice of vehicle translation and suspension calculus as well as the calculus of the dynamics of braking found in the 
theory of a vehicle.

- In line with these requirements to construct reasonably and to apply new special equipment for experimental vehicle research related to oscillations of vehicle flexible mounted and inflexible mounted masses under maximum acceleration of deceleration. In the process of developing new experimental equipment it is necessary to foresee not only the methods of its application, but also the utmost precision methods for the evaluation of the oscillating systems formed in the created constructions.

- To perform experimental research of vehicle oscillations under natural conditions of braking, thus aiming the comparison of actually observed processes with the results of theoretical investigation of the mathematical model. To evaluate the influence of vehicle oscillations found in braking on the indices of a braking process and its effectiveness.

- To develop practical application of the results of theoretical and experimental research regarding the novelty of setting the task as well as the newness of experimental equipment for testing vehicle motion.

\section{Computer modelling of vehicle oscillations during a braking process}

The development of a mathematical model of the process under consideration requires certain assumptions enabling analytical solution of the problem of vehicle oscillation. The essence of this problem is the comparison of oscillations of a vehicle in emergency braking with those found when a vehicle is in the mode of uniform translation. In order to identify the differences of the above types of oscillation, maintaining the equivalent oscillation system at the same level of complexity as found in the theory of uniform translation and vehicle suspension, the evaluation of certain relationships should not be taken into account or evaluated. The latter refers to some minor kinematical relations of the revolving wheels and supporting frame (plane) [5].

Fig 1 show system of axes defining the location of flexible mounted mass at the moment. Their interrelationship can be expressed in the following way:

$$
z_{0}=\frac{z_{2} a+z_{1} b}{a+b} ; \quad \alpha=\frac{z_{1}-z_{2}}{a+b} .
$$

Braking forces acting on the wheels cause vertical forces proportional to their sum acting on the vertical mounted mass in the vertical planes of the front and rear suspension in an opposite direction as shown in the diagram.

Having evaluated the above given expressions and combined the equilibrium equations, it is possible to write the systems of second order differential equations describing the oscillations of the braking vehicle masses [7].

$$
\left\{\begin{array}{l}
\ddot{z}_{1}+2 k_{1}\left(\dot{z}_{1}-\dot{\xi}_{1}\right)+\Omega_{1}^{2}\left(z_{1}-\xi_{1}\right)=-v_{1} r_{1}, \\
\ddot{\xi}_{1}+\omega_{1}^{2} \xi_{1}-2 \frac{k_{1}}{\mu_{1}}\left(\dot{z}_{1}-\dot{\xi}_{1}\right)-\frac{\Omega_{1}^{2}}{\mu_{1}}\left(z_{1}-\xi_{1}\right)=\omega_{1}^{2} q_{1}, \\
\ddot{z}_{2}+2 k_{2}\left(\dot{z}_{2}-\dot{\xi}_{2}\right)+\Omega_{2}^{2}\left(z_{2}-\xi_{2}\right)=-v_{2} r_{2}, \\
\ddot{\xi}_{2}+\omega_{2}^{2} \xi_{2}-2 \frac{k_{2}}{\mu_{2}}\left(\dot{z}_{2}-\dot{\xi}_{2}\right)-\frac{\Omega_{2}^{2}}{\mu_{2}}\left(z_{2}-\xi_{2}\right)=\omega_{2}^{2} q_{2} .
\end{array}\right.
$$

A standard car possessing the following characteristics was selected for testing:

$M=950 \mathrm{~kg} ; M_{1}=600 \mathrm{~kg} ; M_{2}=350 \mathrm{~kg} ; m_{1}=70 \mathrm{~kg} ;$ $m_{2}=80 \mathrm{~kg} ; \quad a=1,38 \mathrm{~m} ; \quad b=1,29 \mathrm{~m} ; \quad h_{c}=0,52 \mathrm{~m}$; $c_{s p 1,2}=34 \mathrm{kN} / \mathrm{m} ; c_{p 1,2}=120 \mathrm{kN} / \mathrm{m} ; \eta_{1}=1,9510^{3} \mathrm{~kg} / \mathrm{s}$; $\eta_{2}=2,0210^{3} \mathrm{~kg} / \mathrm{s}$.

The application programs (software) were developed in Compaq Visual Fortran Professional v 6.1. for the computer aided test. The computer aided modelling is performed in two stages.

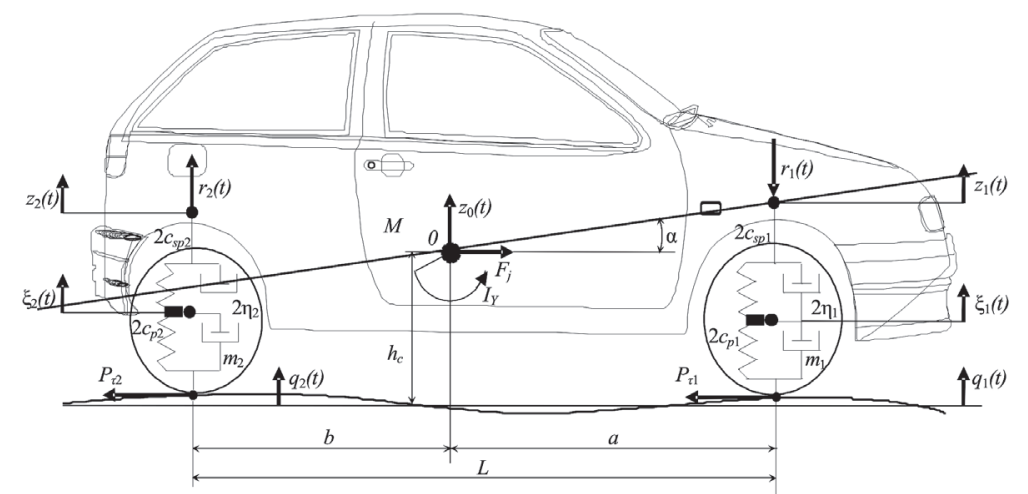

Fig 1. Schematic view of oscillating system equivalent to a vehicle in a braking mode with basic parameters and coordinates 
During the first stage the braking takes place on the even road, i. e. $q_{1}=0, q_{2}=0$.

Fig 2 presents the time dependence of displacements $z_{0}$ of the centre of gravity of the flexible mounted mass of the vehicle in braking on the even road.

During the second stage of the computer-aided modelling the array of quantities of real road microprofile is introduced into the program. In the modelling of the oscillations of a vehicle in braking, the magnitudes of asphalt-concrete road pavement microprofile are used for calculation (Fig 3). Records were obtained by performing the road surface measurements by the laser profileograph DYNATEST 5051 RSP [1].

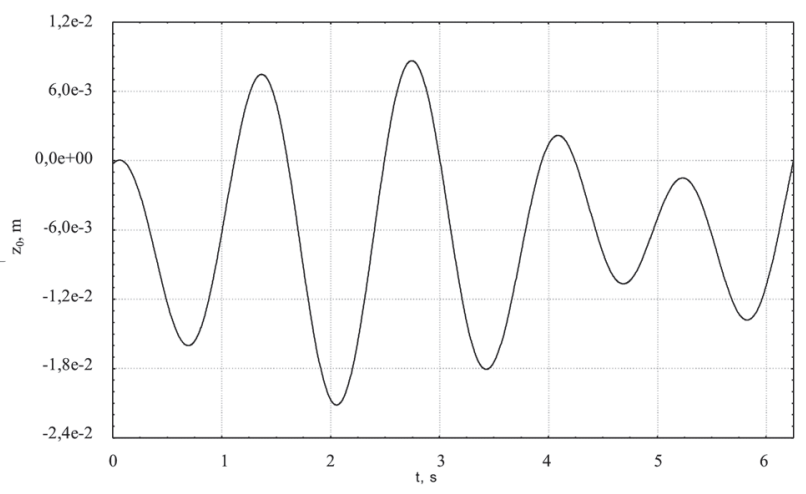

Fig 2. Displacements $z_{0}$ of the centre of gravity of the flexible mounted mass in the modelling of vechicle braking on the even road

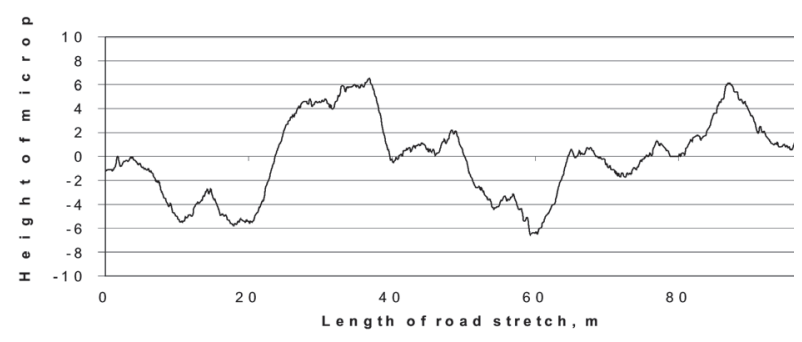

Fig 3. The height of microprofile irregularities of the asphaltconcrete covered $100 \mathrm{~m}$ road stretch

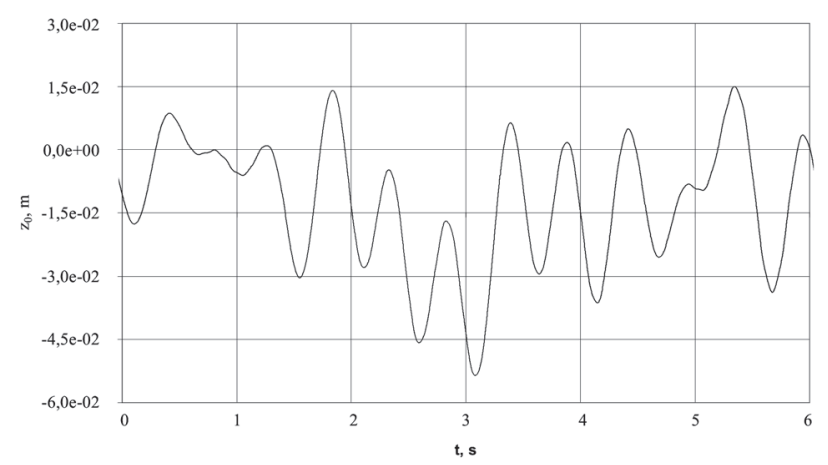

Fig 4. Displacements $z_{0}$ of the centre of gravity of the flexible mounted mass in the modelling of vehicle braking on the asphalt-concrete pavement
Fig 4 presents the time dependence of displacements $z_{0}$ of the centre of gravity of the flexible mounted mass of the vehicle in braking on the asphalt-concrete pavement.

\section{Experimental research into the process of vehicle braking}

An experiment was carried out for the verification of the results obtained in the modelling of oscillations of a vehicle in braking. For this the vibration processing system VAS-21 was applied fitted for synchronous operation with VZM 100 meter of acceleration of deceleration. Pedalling of the vehicle brake goes together with the attached power sensor (Fig 5). When the latter is actuated, the signal indicating the start of measurement reaches two meters - VZM 100 and VAS-21. VZM 100 meter of acceleration of deceleration, having recorded the whole process of vehicle braking, transmits the data through the serial interface RS 232 into the personal computer. The vibration processing system VAS-21 operates in parallel and controls VD 1, VD 2, VD 3, VD 4 vibration sensors attached to the flexible and inflexible mounted masses of the vehicle. Oscillations of the flexible mounted mass of the vehicle in the process of braking were registered by the sensors attached to the vehicle body above the front and rear axles. Sensors registering the oscillations of the inflexible mounted mass were attached directly to the front and rear suspensions. Signals registered by the sensors are sent to the

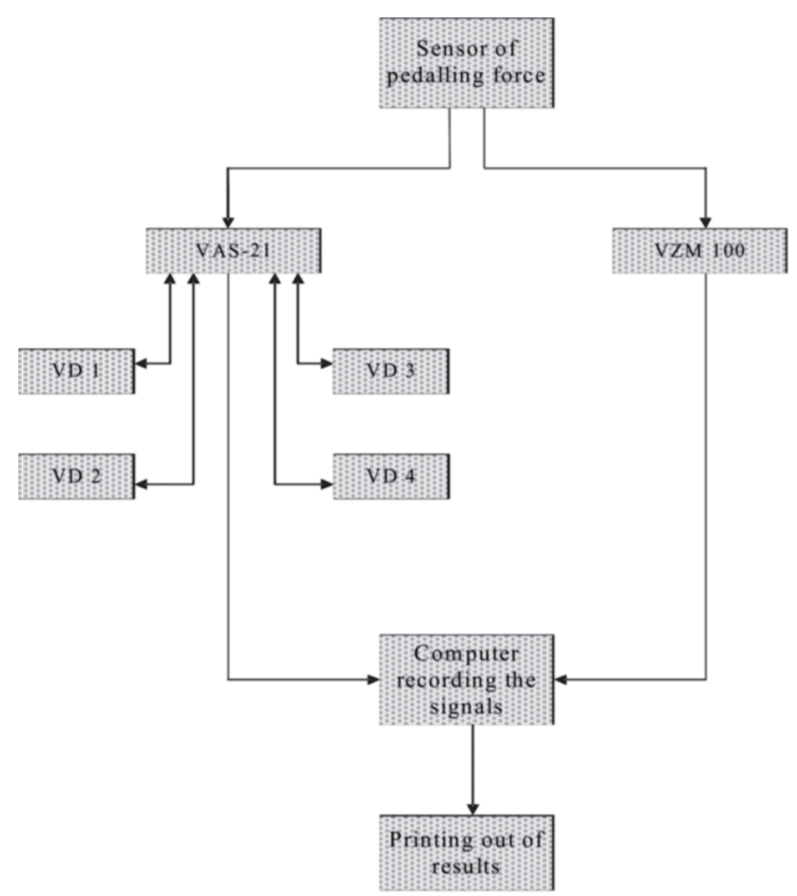

Fig 5. Chart of the equipment for the exploration of oscillations of a vehicle in braking 
vibration processing system and from it into the signal-registering computer.

The experimental equipment for the exploration of oscillations of the vehicle in the process of braking was installed on the car Toyota Carina E. It is assumed that the impact of the road is symmetrical on the right and left side wheels of the vehicle, therefore the oscillations of the right side flexible mounted and inflexible mounted masses are measured. Low frequency sensors $793 \mathrm{~L}$ are attached on the flexible mounted mass above the front and rear axles. With the aim of measuring the oscillations of inflexible mounted masses low frequency sensors of the same model are attached to the front and rear wheel-hobs, so that the sensors should record only the oscillations of the braking forces and those caused by the regularities of road.

After the analysis of vehicle flexible mounted and inflexible mounted masses movement parameters, it was decided to apply vibrodisplacement spectrum records for the analysis of the results. Vibration spectrum analysis enables more precise evaluation of separate frequency components, the definition of causes of their origin and the type of alteration. Experimental investigations were performed on the same stretch of an asphalt-concrete paved road the measured magnitudes of microprofile irregularities of which were used during the computer modelling. It is obvious from Figure 6 that the growth of the acceleration of deceleration of the vehicle causes intensive vertical oscillations of the flexible mounted mass.

The research into the oscillations of the vehicle in its most responsible and dangerous movement modes, i. e. in the process of braking demonstrated the urgency of this issue as well as the opportunities of its solution. Setting and formulation of new research issues of the theory of uniform movement and damping of the vehicle induced the elaboration of the plan

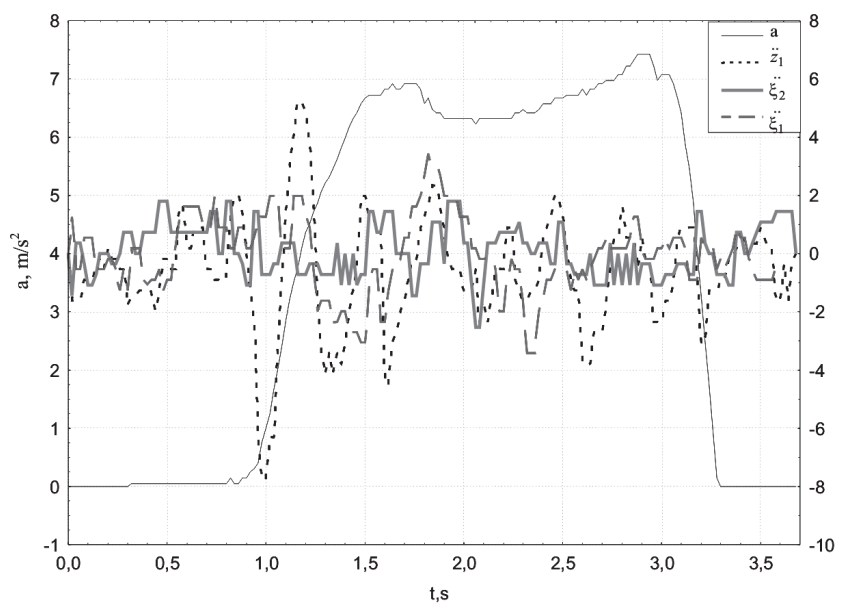

Fig 6. Oscillations of flexible mounted $\left(\ddot{z}_{1}\right)$ and inflexible mounted $\left(\ddot{\xi}_{1}, \ddot{\xi}_{2}\right)$ masses under the alteration of the acceleration of deceleration of the vehicle $(a)$ and program for the work in three interrelated stages. The first stage comprises the development of theoretical models of the explored oscillation processes. The basic feature of this stage consists of the selection of mathematical description mode of the task by coupling two models from the adjacent chapters of the vehicle theory, i. e. from the uniform translation and braking dynamics. Such coupling does not contradict the physical sense of the set task, however, the solution of the problem becomes more complicated in terms of mathematics.

Theoretical research showed that the main role in the explored objects was played by the scarcely investigated effectiveness of the impact of dampers on the vehicle in braking. This is firstly related to the parameters of damper depression when suspensions are affected simultaneously by normal forces of the road and by the tangential braking forces. Actually this comprised the second stage of the solution of the set task. For its performance an experimental basis had to be developed including the capacitating of technical conditions, the construction of new equipment for vehicle testing under the conditions corresponding to the motions of the vehicle in braking. Also the equipment for measuring and registering of the research results was selected and mastered, as well as the methods of its mounting and connecting, and containing, and vibroisolation. The main feature of this stage was the fact that for practical application of the new equipment in experiments new methods of exploration were developed and perfected as well as corresponding models were used for the processing and presentation of the results of the methods.

The third stage of the research was performed as the approval of the results obtained in theoretical, road experimental and stand explorations of the first and the second stages performed on a fully equipped vehicle. The exclusiveness of the research in this stage was that theoretical solutions of the vehicle oscillations during the process of emergency braking were compared to the experimental results obtained in braking of the vehicle on the road, also the application of the results in certain practical investigations of circumstances of traffic incidents/accidents.

\section{Conclusions}

1. The amplitudinal-frequentative characteristics of the displacement of the front flexible mounted mass of the vehicle used for the experiments when wheels were blocked in the road with the adhesion coefficient $\mu=0,8$, has the resonant mode the frequency of which equals to $7,5 \mathrm{~Hz}$, and extreme values $-70 \mathrm{~mm}$. Whereas that of the vehicle in non-braking $-7,5 \mathrm{~Hz}$ with extreme equalling to $24 \mathrm{~mm}$. 
2. The results obtained during the theoretical research of oscillations of the vehicle in emergency braking on a asphalt-concrete road (Fig 4) show that the displacements of the flexible mounted and inflexible mounted masses of the vehicle are twice as intense as the displacements of these masses on the ideally even road (Fig 2). Experiments demonstrate that the uniformity of movement of the vehicle in braking varies according to the increase of the oscillations intensity. In abrupt braking on the rough road, if compared with the braking when the road profile is not taken into account, the maximum displacement amplitudes of the front flexible mounted mass increase by $58 \%$, and respectively that of the back flexible mounted mass by $49 \%$, and the maximum values of the accelerations of front and back flexible mounted masses increase by $50 \%$.

3. The calculation method of the mathematical model of oscillations of the vehicle in emergency braking has been performed within the system of the application programme Compaq Visual Fortran Professional v 6.1. During the investigation of traffic accidents a model was developed enabling the evaluation of the intensity of the pitch and displacement of the mounted flexible mass (according to the set parameters of oscillations), thus giving an opportunity to define the mode of vehicle movement before the traffic accident. Herewith the method of calculation of oscillations of the vehicle in braking enables the evaluation of changeability of braking forces occurring in the zone of the contact of wheels with the road in the result of oscillations of the vehicle in braking.

\section{References}

1. Dimaitis, M.; Sapragonas, J. Description of road pavement with purpose of simulation of automobile suspensions. Transport Engineering (Transportas), Vol XV, No 2, Vilnius: Technika, 2000, p. 72-76 (in Lithuanian).

2. Lee, H.; Tomizuka, M. Coordinated longitudinal and lateral motion control of vehicles for IVHS. J. Dynamic System, Measurement and Control, Vol 123, 2001, p. 535543.

3. Ohsaku, S.; Nakayama, T.; Kamimura, I.; Motozono, Y. Nonlinear $H_{\infty}$ control for semi-active suspension. JSAE Review, Vol 20, 1999, p. 447-452.

4. Tamboli, J. A.; Joshi, S. G. Optimum design of a passive suspension system of a vehicle subjected to actual random road excitations. Journal of Sound and Vibration, Vol 219 (2), 1992, p. 193-205.

5. Lukoševičienè, O.; Bogdevičius, M.; Nagurnas, S.; Pečeliūnas, R. Comparative research of a motor car motion in the case of the loss of contact with the road surfase. Transport, Vol XIX, No 1, Vilnius: Technika, 2004, p. 20-23.

6. Lukoševičiene, $\mathrm{O}$. The accident analysis and simulation: monograph (Autoịvykių analizè ir modeliavimas). Vilnius: Technika, 2001. 244 p. (in Lithuanian).

7. Pečeliūnas, R.; Lukoševičienè, O.; Prentkovskis, O. A mathematical model of the vibrating system equivalent to the vehicle in the mode of emergency braking. Transport, Vol XVIII, No 3, Vilnius: Technika, 2003, p. 136142. 